\title{
Malignant Triton Tumor of the Sciatic Nerve as a Secondary Malignancy after Extended Field Radiotherapy and Chemotherapy of Hodgkin's Disease
}

\author{
Mirko Nitsche ${ }^{a, b} \quad$ Michael Reible $^{a} \quad$ Karl-Heinz Pflüger ${ }^{c}$ \\ Markus Bergmann ${ }^{d}$ Robert Michael Hermann ${ }^{a}$ e \\ ${ }^{a}$ Zentrum für Strahlentherapie und Radioonkologie, Bremen/Westerstede, ${ }^{b}$ Klinik für \\ Strahlentherapie, Karl-Lennert-Krebscentrum, Universität Kiel, Kiel, ' $A b t e i l u n g$ für \\ Hämatologie und internistische Onkologie, DIAKO Bremen, and ${ }^{d}$ Institut für \\ Neuropathologie, Klinikum Bremen Mitte, Bremen, and ${ }^{\mathrm{e}}$ Abteilung Strahlentherapie und \\ spezielle Onkologie, Medizinische Hochschule Hannover, Hannover, Germany
}

\section{Key Words}

Triton tumor · Radiotherapy $\cdot$ Second malignancy $\cdot$ Hodgkin's disease

\begin{abstract}
Late effects of therapy for Hodgkin's disease include secondary malignancies like leukemia, lymphoma or solid tumors developing after long periods of latency. Ionizing radiation often causes the last group. The highest risks have been described for induced breast and lung cancers. We are the first to report a malignant triton tumor (MTT) as a secondary malignancy after radiotherapy and chemotherapy for Hodgkin's lymphoma. MTT is a very rare subtype of malignant peripheral nerve sheath tumors with rhabdomyoblastic differentiation and an aggressive course of disease.

(c) 2014 S. Karger AG, Basel
\end{abstract}

\section{Case Presentation}

At the first diagnosis of Hodgkin's lymphoma (CSIIIA), the patient was 15 years of age (fig. 1). He received total lymphoid irradiation with a cobalt-60 unit. The field configuration consisted of a mantle field (including the major lymph node regions above the diaphragm) 
Nitsche et al.: Malignant Triton Tumor of the Sciatic Nerve as a Secondary Malignancy after Extended Field Radiotherapy and Chemotherapy of Hodgkin's Disease

up to 33.4 Gy and an inverted Y field (including the retroperitoneal, iliac and inguinal lymph nodes) up to 30 Gy with an additional paravertebral/para-aortal (L2/L3) boost of 6 Gy to the tumor region. Afterwards, 2 cycles of COPP chemotherapy (cyclophosphamide, vincristine, procarbazine, prednisolone) were applied.

Twenty-one years later, the patient developed progressive pain in the left gluteal muscle. An MRI scan showed a tumorous mass of $3 \times 4.4 \mathrm{~cm}$ in the left gluteal region expanding to the greater trochanter. A microsurgical operation revealed an isolated tumor of the left sciatic nerve, unfortunately with an $\mathrm{R} 2$ resection status.

\section{Pathology}

The pathological specimen consisted of multiple, gray-white pieces of hard consistency measuring about $13 \times 8 \times 4 \mathrm{~cm}$ in diameter. Microscopically, the tumor tissue was streaked by 'geographic' zones of necrosis and surrounded by a pseudocapsule of dense collagenous tissue. The density of the tumor cells varied. In areas of high-cell density, the tumor cells consisted of plump spindle cells, sometimes with wavy nuclei, which showed a high chromatin density. The mitotic rate was high (31 mitoses/10 HPF). The tumor cells lay concentrically around delicate vessels, in which they sometimes herniated. In areas of lowercell density, the tissue was sometimes of a myxoid quality. Rarely, the tumor cells grew in fascicles or concentric eddies. Scattered, large, polygonal, eosinophilic cells were crowded with eosinophilic filaments (rhabdomyoblasts) and some elongated cells with crossstriations were seen. There were foci of chondroid differentiation (fig. 2, fig. 3).

\section{Clinical Course of the Disease}

Two months after the microsurgical operation, the tumor had regrown up to $9.9 \times 4.7 \times$ $5.9 \mathrm{~cm}$ (fig. 4). A second microsurgical operation was undertaken with neurolysis and decompression of the left sciatic nerve, again resulting in $\mathrm{R} 2$ resection margins. This time, the patient refused a complete resection of the sciatic nerve as he feared the unavoidable loss of function. Yet another 2 months later, during the planning phase of local radiotherapy, further imaging showed a fulminant progress of the disease. Accordingly, the treatment plans were changed, and 1 cycle of VIDE chemotherapy (vincristine, ifosfamide, doxorubicin, etoposide) without doxorubicin and 1 cycle of I ${ }^{2} V A$ (ifosfamide, vincristine, actinomycin-D) chemotherapy were applied in a pseudoneoadjuvant attempt. At restaging, progressive disease was again diagnosed, and another 2 cycles of $I^{2} \mathrm{VA}$ were applied, ultimately resulting in a stable disease.

In a curative attempt, the tumor including the sciatic nerve was resected during a third operation with a narrow R0 resection status $(1 \mathrm{~mm})$. Another 2 months later, an MRI scan showed 7 satellite metastases distributed in the initial tumor region. Hyperfractionated radiotherapy was applied to the whole region with 1.2 Gy twice daily up to 50.4 Gy in a curative attempt. The loco-regional metastases received an additional boost dose of $14.4 \mathrm{~Gy}$, resulting in a cumulative dose of $64.8 \mathrm{~Gy}$ (fig. 5). Despite intensive treatment, the disease progressed rapidly, leading to an exulcerating local tumor. Ultimately, the patient underwent left hemipelvectomy with a narrow R0 resection status. Only half a year later, the patient experienced extensive local progress and pulmonary metastases. He died of uncontrollable bleeding despite embolization. 


\section{Discussion}

Generally, the traditional Cahan criteria are used to define radiation-induced malignancy [1], i.e. (1) the disease must have arisen in the irradiated field with (2) a latency period of $>4$ years between irradiation and induced malignancy, (3) the induced tumor must have undergone biopsy and (4) the tissue of the induced tumor must have been normal prior to radiation exposure. All 4 points are fulfilled in the reported case. Secondary solid tumors in Hodgkin's disease are mostly related to radiotherapy and occur with a long latency period of more than 7 years. There is a 5.6 -fold increased risk for secondary female breast cancer (57 cases $/ 10,000$ persons/year) and an increased risk for secondary lung cancer after doses as low as $5 \mathrm{~Gy}$, especially when patients continue to smoke after therapy $[2,3]$. The relative risk of developing a secondary malignancy after combined modality treatment for Hodgkin's disease is 2.3-2.9 with an absolute risk of 44.5 cases/10,000 patients/year, including leukemia, lymphoma and solid tumors [4, 5].

A malignant peripheral nerve sheath tumor with rhabdomyosarcomatous differentiation was first described by Masson in 1932 [6]. This tumor is defined by histological and immunohistochemical features of a malignant peripheral nerve sheath tumor with focal rhabdomyosarcomatous elements or as a rhabdomyosarcomatous tumor with focal nerve sheath elements, which occur in a peripheral nerve or in neurofibromatosis type 1 (NF-1) [7, 8]. Histology and immunohistochemistry are the mainstay of diagnosis: The tumor cells express S100, desmin, muscle-specific actin, myosin, vimentin, myoglobin and, as in the present case, MyoD1 and Myf4.

Malignant triton tumor (MTT) is associated with NF-1 in $50-70 \%$ of all cases, where it is diagnosed at a younger age and predominantly in males. Patients without NF-1 are diagnosed at a mean age of 32 years with an equal sex distribution. The overall survival rate is low with only $26 \%$ in both groups. The local recurrence rate is about $40 \%$, metastases occur in about $50 \%[9,10]$. Survival depends on the location of the disease, as patients with MTT of the head and neck or extremities generally have a longer life expectancy than those with MTT of the gluteal region, trunk or retroperitoneum [6, 9, 11-13]. The extent of the excision is another factor with a significant impact on the local outcome and survival, as wide resection margins usually result in a better response to adjuvant treatment and better outcome $[9,11,14]$. Therefore, the treatment of MTT must compulsorily start with a complete resection and large resection margins whenever possible.

In our case, the tumor was localized in the left gluteal region surrounding the left sciatic nerve. The patient's initial wish was to preserve the function of the sciatic nerve with minimal surgery. For this reason, the necessary radical approach with adequate margins was omitted. However, soon after the third operation - eventually with a complete resection of the tumor with an R0 resection status at close margins - local recurrence developed during the planning phase of adjuvant radiotherapy, so that ultimately chemotherapy and hemipelvectomy had to be performed.

Up to date, the effectiveness of adjuvant therapy in MTT is still undefined, as no prospective randomized trials are available. In most of the reported cases, the disease progressed rapidly despite adjuvant chemotherapy and radiotherapy $[8,11,13]$. However, it has been suggested that adjuvant therapies may prolong survival after the radical resection of the MTT [7, 15-17]. 


\section{Case Reports in Oncology}

\begin{tabular}{l|l}
\hline Case Rep Oncol 2014;7:239-245 & \multicolumn{2}{l}{} \\
\hline DOI: $10.1159 / 000360576$ & $\begin{array}{l}\text { C 2014 S. Karger AG, Basel } \\
\text { www.karger.com/cro }\end{array}$ \\
\hline
\end{tabular}

Nitsche et al.: Malignant Triton Tumor of the Sciatic Nerve as a Secondary Malignancy after Extended Field Radiotherapy and Chemotherapy of Hodgkin's Disease

\section{References}

1 Cahan WG, Woodard HQ, Higinbotham NL, Stewart FW, Coley BL: Sarcoma arising in irradiated bone: report of eleven cases. 1948. Cancer 1998;82:8-34.

2 Travis LB, Gilbert E: Lung cancer after Hodgkin lymphoma: the roles of chemotherapy, radiotherapy and tobacco use. Radiat Res 2005;163:695-696.

3 De Bruin ML, Sparidans J, van't Veer MB, Noordijk EM, Louwman MW, Zijlstra JM, van den Berg H, Russell NS, Broeks A, Baaijens MH, Aleman BM, van Leeuwen FE: Breast cancer risk in female survivors of Hodgkin's lymphoma: lower risk after smaller radiation volumes. J Clin Oncol 2009;27:4239-4246.

-4 Dores GM, Metayer C, Curtis RE, Lynch CF, Clarke EA, Glimelius B, Storm H, Pukkala E, van Leeuwen FE, Holowaty EJ, Andersson M, Wiklund T, Joensuu T, van't Veer MB, Stovall M, Gospodarowicz M, Travis LB: Second malignant neoplasms among long-term survivors of Hodgkin's disease: a population-based evaluation over 25 years. J Clin Oncol 2002;20:3484-3494.

5 Swerdlow AJ, Higgins CD, Smith P, Cunningham D, Hancock BW, Horwich A, Hoskin PJ, Lister TA, Radford JA, Rohatiner AZ, Linch DC: Second cancer risk after chemotherapy for Hodgkin's lymphoma: a collaborative British cohort study. J Clin Oncol 2011;29:4096-4104.

6 Masson P: Recklinghausen's Neurofibromatosis, Sensory Neuromas and Motor Neuromas. Libman Anniversary. 2 vol. New York, International Press, 1932, pp 793-802.

7 Li Z, Xiang J, Yan S, Gao F, Zheng S: Malignant triton tumor of the retroperitoneum: a case report und review of the literature. World J Surg Oncol 2012;10:96.

-8 Stasik CJ, Tawfik 0: Malignant peripheral nerve sheath tumor with rhabdomyosarcomatous differentiation (malignant triton tumor). Arch Pathol Lab Med 2006;130:1878-1881.

-9 Yakulis R, Manack L, Murphy AI Jr: Postradiation malignant triton tumor. A case report and review of the literature. Arch Pathol Lab Med 1996;120:541-548.

-10 Haddadin MH, Hawkins AL, Long P, Morsberger LA, Depew D, Epstein JI, Griffin CA: Cytogenetic study of malignant triton tumor: a case report. Cancer Genet Cytogenet 2003;144:100-105.

11 Brooks JS, Freeman M, Enterline HT: Malignant 'Triton' tumors. Natural history and immunohistochemistry of nine new cases with literature review. Cancer 1985;55:2543-2549.

12 Daimaru Y, Hashimoto H, Enjoji M: Malignant 'triton' tumors: a clinicopathologic and immunohistochemical study of nine cases. Hum Pathol 1984;15:768-778.

13 Victoria L, McCulloch TM, Callaghan EJ, Bauman NM: Malignant triton tumor of the head and neck: a case report and review of the literature. Head Neck 1999;21:663-670.

14 Enneking WF, Spanier SS, Goodman MA: A system for the surgical staging of musculoskeletal sarcoma. Clin Orthop Relat Res 1980;153:106-120.

15 Koutsopoulos AV, Mantadakis E, Katzilakis N, Lagoudaki ED, de Bree E, Stiakaki E, Kalmanti M: Long-term survival of a patient with a neurofibromatosis Type 1 associated retroperitoneal malignant triton tumor after multi-modality treatment. Clin Neuropathol 2011;30:333-335.

16 Lang-Lazdunski L, Pons F, Jancovici R: Malignant 'Triton' tumor of the posterior mediastinum: prolonged survival after staged resection. Ann Thorac Surg 2003;75:1645-1648.

17 Kostler WJ, Amann G, Grunt TW, Singer CF, Schneider SM, Brodowicz T, Tomek S, Zielinski CC: Recurrent malignant Triton tumour: first report on a long time survivor. Oncol Rep 2003;10:533-535. 


\section{Case Reports in Oncology}

\begin{tabular}{l|l}
\hline DOI: $10.1159 / 000360576$ & $\begin{array}{l}\text { C 2014 S. Karger AG, Basel } \\
\text { www.karger.com/cro }\end{array}$ \\
\hline
\end{tabular}

Nitsche et al.: Malignant Triton Tumor of the Sciatic Nerve as a Secondary Malignancy after Extended Field Radiotherapy and Chemotherapy of Hodgkin's Disease
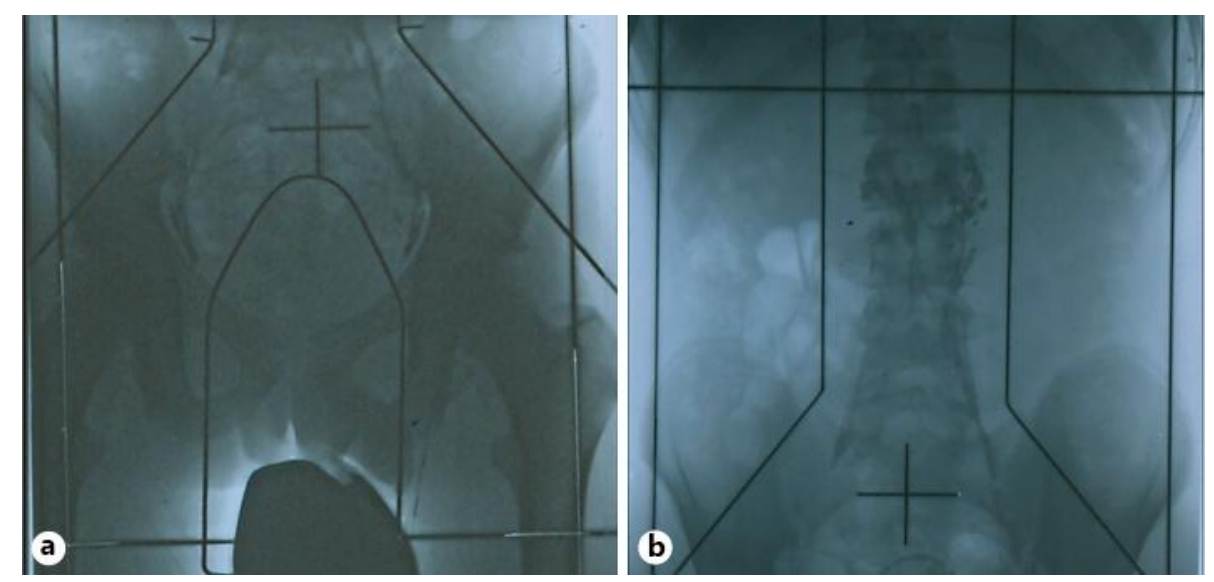

Fig. 1. Total lymphoid irradiation with a cobalt-60 unit. The subdiaphragmal field configuration consisted of an inverted Y field including the retroperitoneal, iliac and inguinal lymph nodes. Treatment planning included a lymphography with lipiodol. At the left hilum of the kidney, pathological lymph nodes were visible; they received an additional boost dose.

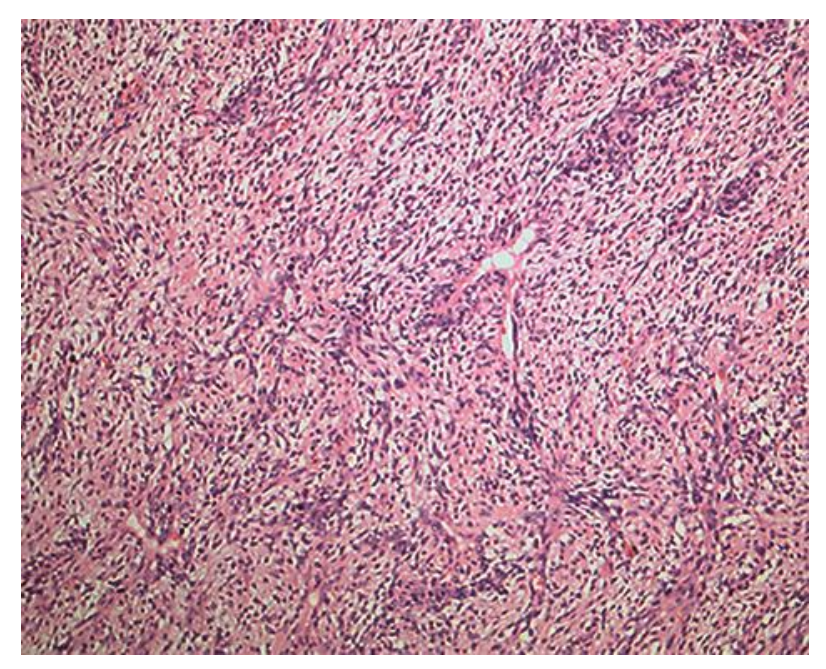

Fig. 2. Myxoid tumor tissue with cell whorls herniating rarely into the vascular lumina (HE, original magnification: $\times 100$ ). 


\section{Case Reports in Oncology}

\begin{tabular}{l|l}
\hline \multicolumn{2}{l}{ Case Rep Oncol 2014;7:239-245 } \\
\hline DOI: 10.1159/000360576 & $\begin{array}{l}\text { C 2014 S. Karger AG, Basel } \\
\text { www.karger.com/cro }\end{array}$ \\
\hline
\end{tabular}

Nitsche et al.: Malignant Triton Tumor of the Sciatic Nerve as a Secondary Malignancy after Extended Field Radiotherapy and Chemotherapy of Hodgkin's Disease

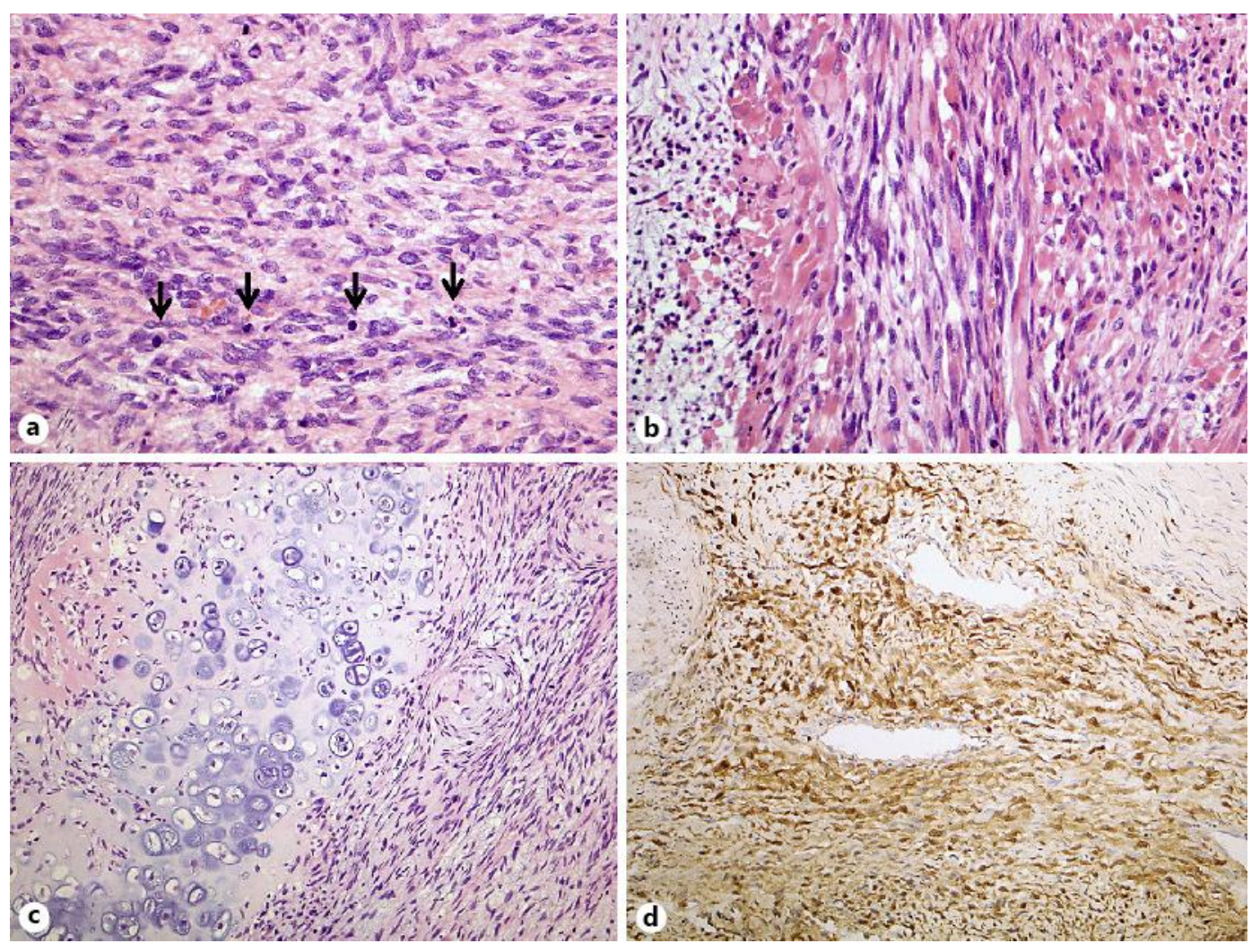

Fig. 3. a Tumor tissue consisting of plump spindle cells with many mitoses marked by arrows (HE). b Cytoplasma-rich polygonal cells (so-called rhabdomyoblasts) and elongated multinucleated strap cells (HE). c Tumor tissue made up of spindle cells and a chondroid area with a hyaline matrix and lacunar cells (HE). $d$ S100-positive tumor cells in a perivascular location (anti-S100, ABC). Original magnification: $\times 200$ in $\mathbf{a}$ and $\mathbf{b}, \times 100$ in $\mathbf{c}$ and $\mathbf{d}$.

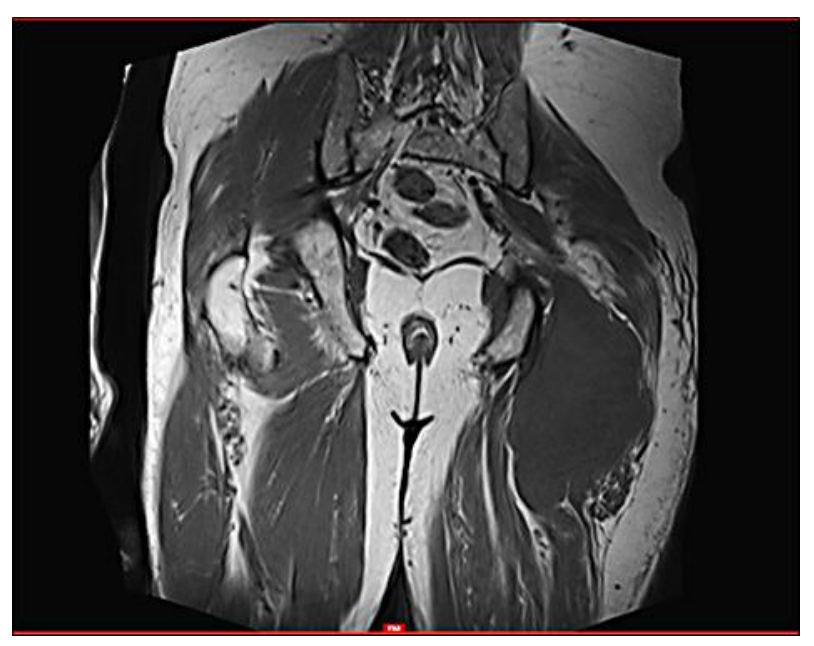

Fig. 4. Coronal T1-weighted MRI scan revealing the recurrent disease. An extensive tumor $(10 \times 5 \times 6 \mathrm{~cm})$ expanding from the left sciatic nerve to the gluteal region. 


\section{Case Reports in Oncology}

Case Rep Oncol 2014;7:239-245

DOI: $10.1159 / 000360576$

(witsche et a : Malignant Triton Tumor of the Sciatic Nerve as a Secondary

Nitsche et al:: Malignant Triton Tumor of the Sciatic Nerve as a Secondary Malignancy after Extended Field Radiotherapy and Chemotherapy of Hodgkin's Disease

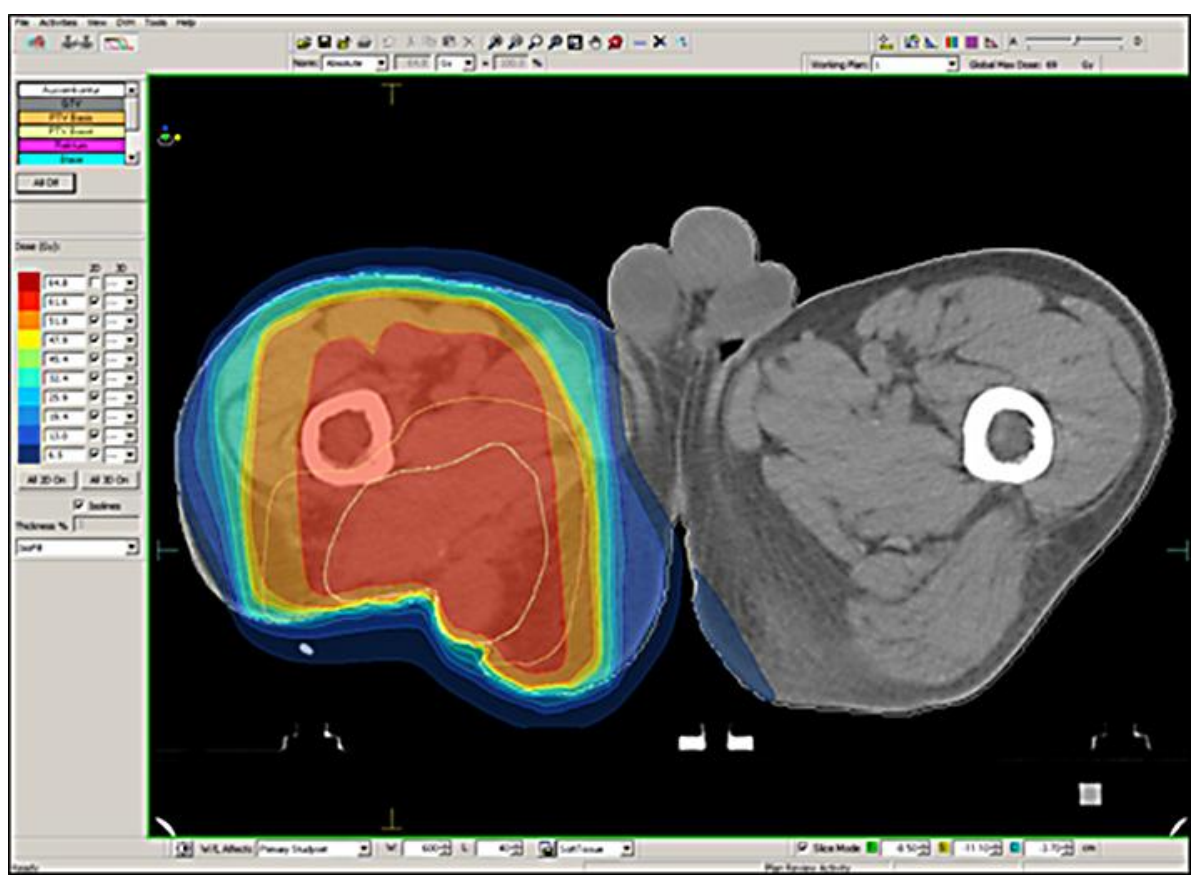

Fig. 5. The dose distribution of the radiotherapy treatment planning: yellow indicates the 95\% isodose of the prescribed dose of $50.4 \mathrm{~Gy}$, red indicates the 95\% isodose of the prescribed boost dose of $64.8 \mathrm{~Gy}-$ representing an additional boost to the region of the recurrent tumor. 